\title{
Long-Term Follow-Up of Myopic Choroidal Neovascularization Treated with Ranibizumab
}

\author{
Nuno Franqueira ${ }^{a}$ M. Luz Cachulo ${ }^{a, b}$ Isabel Pires ${ }^{a, b}$ Pedro Fonseca ${ }^{a, b}$ \\ Inês Marques ${ }^{a}$ João Figueira ${ }^{a, b}$ Rufino Silva ${ }^{a, b}$ \\ ${ }^{a}$ Department of Ophthalmology, University Hospital of Coimbra, and ${ }^{\mathrm{b}} \mathrm{AIBILI}$ - Association for Innovation and \\ Biomedical Research on Light and Image, Coimbra, Portugal
}

\section{Key Words}

Pathological myopia • Choroidal neovascularization •

Ranibizumab · Anti-VEGF

\begin{abstract}
Purpose: To evaluate the long-term safety and efficacy of intravitreal ranibizumab in the treatment of myopic choroidal neovascularization (CNV). Methods: Three-year retrospective, nonrandomized, interventional case series. Forty eyes of 39 patients with myopic CNV were included; 15 with previous photodynamic therapy, and 25 naïve eyes. Bestcorrected visual acuity (BCVA) changes, central foveal thickness (CFT), and number of treatments were assessed, from baseline to month 36. Results: Mean visual acuity improved from 55.4 Early Treatment Diabetic Retinopathy Study (ETDRS) letters at baseline to 59.7 letters at 12 months ( $p=$ $0.07), 61.8$ letters at 24 months $(p=0.008)$ and 63.4 letters at 36 months ( $p=0.039$ ). Twenty-five percent of the patients gained $\geq 15$ letters ( 3 lines) at 12 months, 30\% at 24 months and $35 \%$ at 36 months. There was a mean reduction of $80 \mu \mathrm{m}$ in CFT ( $p<0.001)$. A mean of 4.1 injections were performed in the first year, 2.4 in the second year and 1.1 in the third year. Fifty-three percent of the eyes had no need for treatment during the third year of follow-up. Conclusions: Intravitreal ranibizumab seems to be an effective and safe thera-
\end{abstract}

peutic procedure to treat CNV in highly myopic eyes, with a high proportion of patients gaining or stabilizing BCVA at a 3-year follow-up.

Copyright $\odot 2011$ S. Karger AG, Basel

\section{Introduction}

Pathological myopia is a major cause of legal blindness in developed countries [1]. Choroidal neovascularization $(\mathrm{CNV})$ is an important cause of visual loss among highly myopic patients with a prevalence of $5-11 \%[2,3]$. Pathological myopia is the most common cause of $\mathrm{CNV}$ in young individuals [4]. Natural history of myopic CNV is considered to be poor, with a high proportion of patients having a significant loss of visual acuity [5-8]. Nowadays, photodynamic therapy (PDT) with verteporfin is the only approved treatment by regulatory authorities for myopic CNV. However, in the VIPm study, treated eyes did not achieve the main outcome by the end of the second year of follow-up [9]. Anti-VEGF drugs have been used off-label to treat myopic CNV. We have published the 6-month and 12-month results of myopic CNV treated with intravitreal ranibizumab with good outcomes $[10,11]$. In the present study, we report the 36-month follow-up of myopic CNV treated by intravitreal ranibizumab.

\section{KARGER}

Fax +4161306 1234

E-Mail karger@karger.ch

www.karger.com
C) 2011 S. Karger AG, Basel

$0030-3755 / 12 / 2271-0039 \$ 38.00 / 0$

Accessible online at:

www.karger.com/oph
Nuno Franqueira, MD

Department of Ophthalmology, University Hospital of Coimbra Praceta Mota Pinto

PT-3000 Coimbra (Portugal)

Tel. +351 23940 0449, E-Mail nuno_franqueira777@ @otmail.com 


\section{Patients and Methods}

A retrospective, institutional study was performed in 40 eyes of 39 patients with active subfoveal or juxtafoveal myopic CNV treated with an intravitreal injection (nonloading dose) of $0.5 \mathrm{mg}$ of ranibizumab and followed for 3 years.

Fifteen eyes had previously undergone PDT for myopic CNV at least 3 months before the first ranibizumab treatment. No additional PDT was performed during the follow-up.

The inclusion criteria were: (1) highly myopic eyes with a spherical equivalent $\geq-6 \mathrm{dpt}$ or an axial length $\geq 26.5 \mathrm{~mm}$; (2) posterior fundus myopic changes; (3) active subfoveal or juxtafoveal $\mathrm{CNV}$ on fluorescein angiography; (4) best-corrected visual acuity (BCVA) $\geq 20 / 400$ at baseline, and (5) age over 18 years. The exclusion criteria were: (1) CNV due to other causes than pathological myopia; (2) retinal vasculopathies; (3) patients with subfoveal or juxtafoveal laser scar; (4) patients with previous treatment with other anti-angiogenic drugs (bevacizumab or pegaptanib) or with intravitreal triamcinolone or radiation; (6) ocular hypertension or glaucoma; (7) concomitant disease in the study eye, including uveitis, presence of pigment epithelial tears or rips, acute ocular or periocular infection, and central serous chorioretinopathy; (8) pregnancy or premenopausal women not using adequate contraception, and (9) patients with recent thromboembolic events.

Each patient underwent a complete ophthalmic examination including BCVA on a standard Early Treatment Diabetic Retinopathy Study (ETDRS) chart, slit-lamp examination, ocular tonometry, fundus examination and an optical coherence tomography (OCT; OCT Stratus v. 4.0 and Cirrus HD-OCT v. 2.0; Carl Zeiss Meditec, Inc., Dublin, Calif., USA) at baseline and then every 4-6 weeks during follow-up. Central foveal thickness (CFT) was measured automatically by OCT. We subtracted $60 \mu \mathrm{m}$ from the value obtained with the Cirrus HD-OCT for comparison with the values obtained with Stratus OCT. Fluorescein angiography was performed at baseline for all patients and when in doubt about CNV activity during follow-up. All patients had evidence of fluorescein angiography leakage at baseline that involved the fovea and was responsible for the decrease in visual acuity.

The need for retreatment was determined by a decrease in BCVA and/or metamorphopsia, the presence of intra- or subretinal fluid in the OCT and/or fluorescein angiography subfoveal or juxtafoveal leakage.

Main outcomes were BCVA change (ETDRS letter gain or loss) and CFT change measured by OCT during follow-up. The effects of previous PDT treatment and age on final visual acuity were considered secondary outcomes.

The presence of systemic or ocular side effects was evaluated at each visit during the follow-up time.

The study followed the tenets of the Declaration of Helsinki and was approved by the university clinic research committee. An informed consent document was reviewed and signed by all patients.

Statistical analysis was performed by means of a nonparametric Wilcoxon signed-rank test and two-tailed t test in order to compare continuous variables. Categorical variables were compared using the $\chi^{2}$ test. The influence of age, sex, previous PDT and number of treatments on BCVA change was analyzed by means of multivariate linear regression. A p value $<0.05$ was considered statistically significant. All statistical tests were performed using SPSS version 16.0.1 software (SPSS Inc., Chicago, Ill., USA).

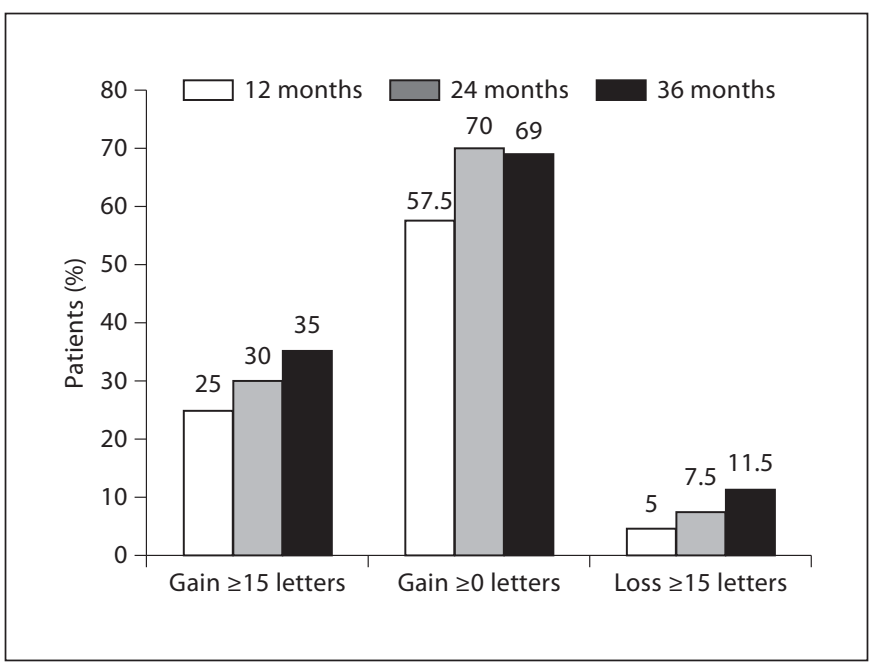

Fig. 1. BCVA change at 12 months $(n=40), 24$ months $(n=40)$ and 36 months $(n=26)$ of follow-up.

\section{Results}

Forty eyes of 39 patients (12 men and 27 women; median age, 55 years; range, $20-89$ years) presenting with active myopic CNV were included in this study and treated with at least one injection of ranibizumab. Fifteen eyes had previously undergone unsuccessful PDT for myopic CNV with a mean of 2.9 sessions. Follow-up was at least 30 months for all eyes, and 26 eyes reached the 3 years of follow-up.

Mean BCVA was 55.4 ETDRS letters at baseline, 59.7 letters at 12 months $(\mathrm{p}=0.07), 61.8$ letters at 24 months $(\mathrm{p}=0.008)$ and 63.4 letters at 36 months $(\mathrm{p}=0.039)$. Twenty-five percent of the patients gained $\geq 15$ letters ( 3 lines) at 12 months, $30 \%$ at 24 months and $35 \%$ at 36 months. An improvement of $\geq 0$ letters occurred in $57.5 \%$ of the patients at 12 months, $70 \%$ at 24 months and $69 \%$ at 36 months. BCVA worsened by $\geq 15$ letters in only 2 patients (5\%) at 12 months, 3 patients (7.5\%) at 24 months and 3 patients (11.5\%) at 36 months (fig. 1). There was no correlation between final BCVA and initial BCVA ( $p=$ 0.07 ). We analyzed the response to intravitreal ranibizumab at 6 months dividing the patients into three groups: responders (gain $\geq 5$ letters); stable (gain between -4 and 4 letters) and nonresponders (loss $\geq 5$ letters). At 6 months, $48.7 \%$ of the eyes were responders, $30.8 \%$ were stable and $20.5 \%$ were nonresponders. The type of response at 6 months was significantly associated with the type of response to intravitreal ranibizumab at 
Fig. 2. Types of response to intravitreal ranibizumab (number of eyes). There was a significant $(\mathrm{p}<0.001)$ association between the type of response at 6 months and the response at 12 months, 24 months and 36 months. $6 \mathrm{M}=6$ months; $\mathrm{NR}=$ nonresponders; $\mathrm{S}=$ stable; $\mathrm{R}=$ responders.

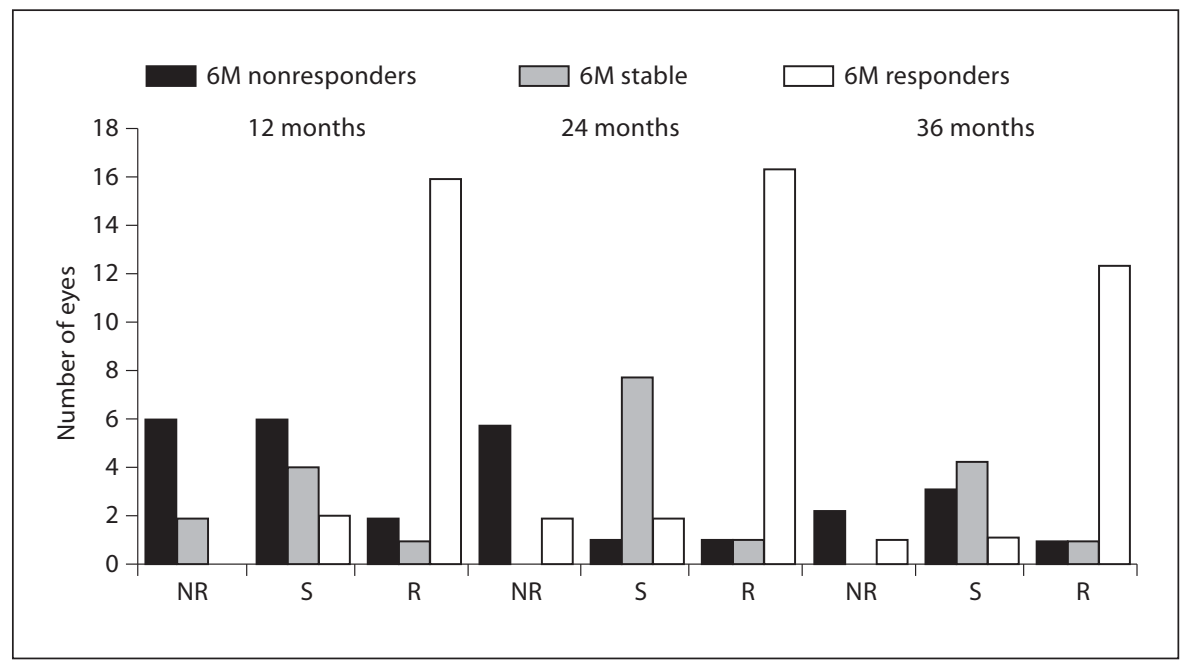

12 months ( $\mathrm{p}<0.001), 24$ months $(\mathrm{p}<0.001)$ and 36 months $(\mathrm{p}<0.001)$ (fig. 2$)$. Mean BCVA change at 6 months was significantly correlated with mean BCVA change at 36 months $(\mathrm{p}<0.001)$.

CFT measured by OCT decreased from a mean of 295 $\mu \mathrm{m}$ (range, $199-630 \mu \mathrm{m}$ ) at baseline to $226 \mu \mathrm{m}$ (range, 115-336 $\mu \mathrm{m}$ ) at 12 months ( $<<0.001), 214 \mu \mathrm{m}$ (range, $99-392 \mu \mathrm{m})$ at 24 months $(\mathrm{p}<0.001)$ and $215 \mu \mathrm{m}$ (range, $136-457 \mu \mathrm{m})$ at 36 months $(\mathrm{p}=0.001)$. CFT change at 36 months was significantly correlated with initial foveal thickness $(\mathrm{p}=0.001)$. Age $(\mathrm{p}=0.94)$, sex $(\mathrm{p}=0.53)$ or previous PDT treatment $(\mathrm{p}=0.46)$ were not correlated with CFT change at 36 months.

A mean number of 7.6 (range, 2-19) treatments were performed during the follow-up time. A mean of 4.1 injections were performed in the first year, 2.4 in the second year and 1.1 in the third year. Twenty-five percent of the patients only had treatments during the first year of follow-up and $57 \%$ of the patients needed no treatment during the third year of follow-up. Final BCVA, previous PDT, sex and age were not significantly correlated with the number of ranibizumab injections $(\mathrm{p}=0.77 ; \mathrm{p}=0.71$; $p=0.28$, and $p=0.55$, respectively). Seventy-five percent of the patients needed 3 injections at the first 3 visits. There was no significant difference in initial BCVA $(\mathrm{p}=$ $0.20)$, final BCVA $(\mathrm{p}=0.89)$, initial CFT $(\mathrm{p}=0.95)$, final CFT $(p=0.10)$, age $(p=0.78)$, or total number of treatments $(\mathrm{p}=0.11)$ between patients who had 3 initial injections and patients who did not. There was no association between previous PDT treatment and the need for 3 initial injections $(\mathrm{p}=0.57)$.

Long-Term Follow-Up of Myopic CNV

Treated with Ranibizumab
A subgroup analysis was performed on eyes with and without previous PDT comparing these two groups regarding baseline characteristics (age, initial visual acuity, initial CFT) and response to intravitreal ranibizumab. No statistical difference ( $p>0.05$ ) was found between patients previously treated with PDT and naïve patients regarding any of the mentioned baseline characteristics, mean BCVA and mean CFT during follow-up or the final number of treatments. The eyes previously treated with PDT (fig. 3) had an improvement in mean BCVA from 55.4 letters at baseline to 60.8 letters at 12 months ( $\mathrm{p}=$ $0.15), 63.9$ letters at 24 months $(\mathrm{p}=0.057)$ and 62.3 at 36 months $(\mathrm{p}=0.14)$. Eyes with no previous PDT had an improvement in mean BCVA from 55.3 letters at baseline to 59.1 letters at 12 months $(\mathrm{p}=0.25), 60.6$ letters at 24 months $(\mathrm{p}=0.068)$ and 64.1 letters at 36 months $(\mathrm{p}=$ $0.16)$.

Visual acuity improvement was significantly associated with age $(p=0.03)$. Patients aged less than 55 years had an improvement in BCVA from 54.1 letters at baseline to 63.1 letters at 12 months $(\mathrm{p}=0.02), 64.1$ letters at 24 months $(\mathrm{p}=0.006)$ and 67.7 letters at 36 months $(\mathrm{p}=$ 0.001 ). Patients aged 55 or more years had an improvement in BCVA from 56.5 letters at baseline to 56.3 letters at 12 months $(\mathrm{p}=0.93), 59.3$ letters at 24 months $(\mathrm{p}=0.42)$ and 57.4 letters at 36 months ( $\mathrm{p}=0.53$ ).

No systemic or ocular side effects were registered during follow-up, including endophthalmitis, retinal detachments, ocular hypertension, intraocular inflammation and thromboembolic events. 
Fig. 3. Patient with previous PDT (3 sessions) for myopic CNV. Baseline retinography (a), initial-phase (b) and late-phase (c) fluorescein angiography, and OCT (d) showing leakage from subfoveal neovascularization. Baseline BCVA of 48 letters. OCT at 36 months (e) showing subfoveal hyperreflectivity compatible with the presence of a scar with fibrosis and without intra- or subretinal fluid. This patient had a total number of 5 treatments and a final BCVA of 85 letters.
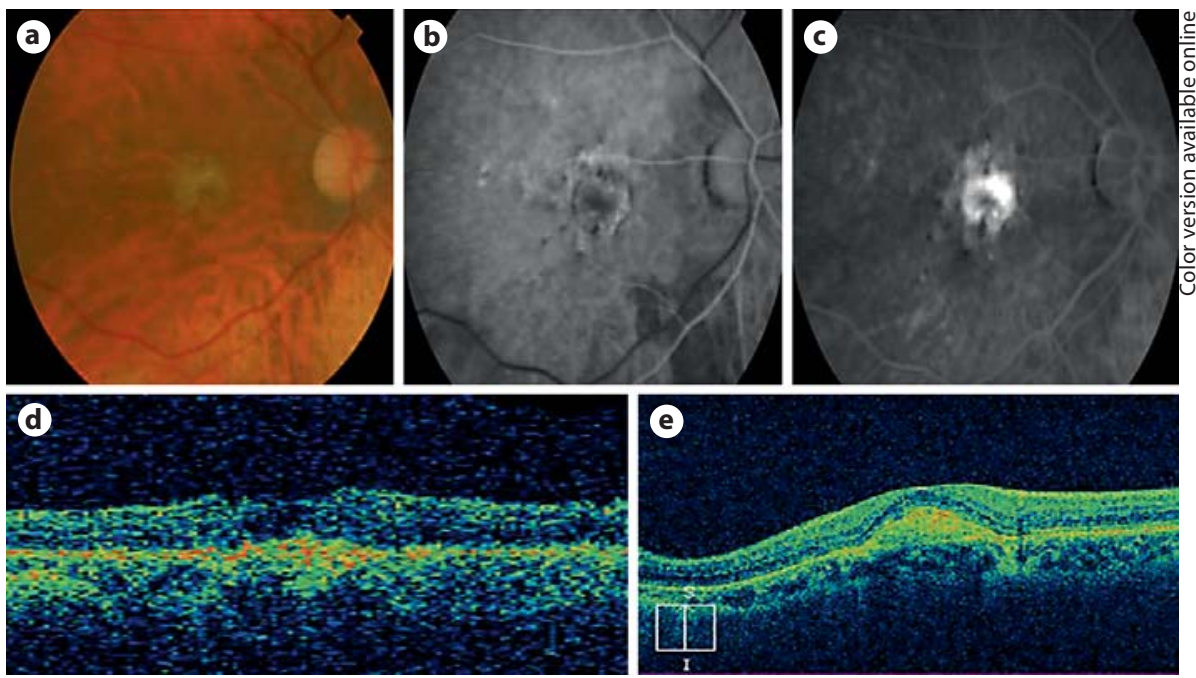

\section{Discussion}

The introduction of anti-VEGF therapies in ophthalmology revolutionized the way we treat the exudative form of age-related macular degeneration (AMD). Ranibizumab is an anti-VEGF drug approved by the US Food and Drug Administration and the European Medicines Agency for the treatment of neovascular AMD, improving and stabilizing visual acuity of most of these patients $[12,13]$. Pathophysiology of myopic CNV is different from CNV secondary to AMD. However, high levels of VEGF seem to be involved in the development of myopic CNV [14]. In theory, a similar response to AMD is expected in patients with myopic CNV treated with intravitreal ranibizumab.

Previous studies reporting clinical experience with ranibizumab in myopic CNV have shown promising results.

Silva et al. $[10,11]$ reported the short-term outcomes of myopic CNV treated with ranibizumab and then confirmed its efficacy at 12 months of follow-up. Mean visual acuity improved by 8 letters with a final BCVA of 59.6 letters at 1 year of follow-up. Twenty-four percent of the patients gained $\geq 15$ letters at 12 months with a mean of 3.6 treatments [10, 11]. Monés et al. [15] reported in a study of 23 patients a mean gain of 9.53 letters at 12 months with $27 \%$ gaining more than 15 letters. Lalloum et al. [16] included 36 eyes in their study and BCVA improved from 0.2 at baseline to a final BCVA of 0.4 with 17 months of follow-up. Forty-six percent of the eyes gained more than 15 letters. In the present study, visual acuity significantly improved with a longer follow-up time. Mean BCVA improved from 55.4 letters at baseline to 59.7 letters at 12 months $(\mathrm{p}=0.07), 61.8$ letters at 24 months $(\mathrm{p}=0.008)$ and 63.4 letters at 36 months $(\mathrm{p}=0.039)$. Twenty-five percent of the patients gained $\geq 15$ letters at 12 months, $30 \%$ at 24 months and $35 \%$ at 36 months. Eyes losing vision at 6 months had a worse visual prognosis. They had a much higher possibility of maintaining a negative score at the end of follow-up. Visual acuity change at 6 months can be a predictive factor of visual outcome $(\mathrm{p}<0.001)$.

We adopted a nonloading dose treatment protocol with a monthly follow-up and then an as-needed treatment regimen, as did the authors of the previously mentioned studies. This decision was based on the assumption that the greater improvement in visual acuity is achieved after the first injection of ranibizumab $[10,11$, 17] and the fact that CNV is generally less extensive in myopic eyes than in eyes with AMD. These eyes have less intra- or subretinal fluid, which may contribute to a better response to intravitreal ranibizumab. A mean of 4.1 injections were performed in the first year, 2.4 in the second year and 1.1 in the third year. The number of treatments was not correlated with final visual acuity and no predictive factors for the need for retreatment were identified. Seventy-five percent of the eyes in our study needed 3 injections at the first 3 visits. However, there was no significant difference in final visual acuity between patients who needed 3 initial injections and patients who did not $(\mathrm{p}=0.89)$. The final BCVA of the eyes who did not need 3 initial injections was 64 letters with a mean of 5.9 
treatments at the end of the 36 months, so we believe that the adoption of a loading dose would be excessive, unnecessary and associated with higher risks. It is still uncertain which is the most effective treatment regimen for myopic CNV, and there are no studies comparing these two treatment modalities (loading dose vs. pro re nata) in the management of myopic CNV with ranibizumab. There are some authors that adopted a loading dose of ranibizumab for myopic CNV. Lai et al. [18], in a study with 16 eyes, noted a mean gain of 3 lines with a mean of 3.8 treatments at the end of 12 months. Eighty-one percent of the eyes only needed the loading dose. CalvoGonzalez et al. [19] included 67 eyes with myopic CNV treated with a loading dose of ranibizumab with a mean follow-up of 15.6 months. They noticed a mean gain of 12 letters at the end of the follow-up with a mean of 4.2 treatments. A total of $53.7 \%$ of the eyes received only 3 injections.

We noticed a significant decrease in CFT measured by OCT during the follow-up time, with a mean decrease of $80 \mu \mathrm{m}$. In our series, a high proportion of patients had their baseline CFT measured with a Stratus OCT and their final CFT measured with a Cirrus HD-OCT. There is a difference in CFT measurement between these two OCTs, and this difference depends on the retinal disease in study [20]. CFT measures by Cirrus OCT are greater than by Stratus OCT. This difference can be explained by the individual segmentation algorithms of the different OCTs. Cirrus OCT identifies the thickness of the retina based on the distance between the inner limiting membrane and the outer band of the retinal pigment epithelium while Stratus OCT performs the outer alignment at the level of the photoreceptor inner/outer segment junction. To compare the two systems, we have made a conversion, subtracting $60 \mu \mathrm{m}$ from the value obtained with Cirrus HD-OCT [21,22], so we have to be careful with the interpretation of our CFT results as there could be some residual errors. Myopic CNV has less intra- and subretinal fluid, and the choroid is usually very thin in these patients, so OCT can sometimes be useless in the decision to treat these patients. That is one of the reasons why we included metamorphopsias as a retreatment criteria.

Visual acuity improvement was obtained in eyes with and without previous PDT treatment, with no significant difference in visual outcome between these two groups. The mechanisms of action of PDT and ranibizumab are different, so patients that had undergone unsuccessful PDT for myopic CNV still have an opportunity for visual acuity improvement when treated with ranibizumab for their recurrent CNV. Authors like Lalloum et al. [16] noticed a significantly higher improvement in visual acuity in naïve patients when compared with patients who had undergone previous PDT. They justified their results by the fact that PDT is often associated with fibrosis of the neovascular membrane and can facilitate the development and progression of chorioretinal atrophy.

A negative significant correlation was observed between age and final visual acuity $(\mathrm{p}=0.03)$. Patients aged less than 55 years had a higher improvement in visual acuity when compared with patients aged 55 or more years. This relation was also demonstrated in previous studies with PDT for myopic CNV [23, 24]. Younger patients have smaller neovascular membranes and a healthier retinal pigment epithelium able to envelop the CNV. On the other hand, older patients have larger areas of chorioretinal atrophy [25] and other age-related retinal changes that could explain a worse visual prognosis.

No cases of endophthalmitis, stroke, or retinal detachment were registered during the follow-up. Particular care was taken to observe the peripheral retina before treatment, and prophylactic topical antibiotics were administered before and after the injection.

In conclusion, our results suggest that intravitreal ranibizumab appears to be safe and effective in the treatment of subfoveal and juxtafoveal myopic CNV. BCVA significantly improves by the end of the third year of follow-up with a high proportion of patients gaining or stabilizing visual acuity. Change in BCVA at 6 months can be a predictive factor of visual outcome. Younger patients seem to have a better prognosis, and no differences were identified in visual outcome between naïve patients and patients with previous PDT for myopic CNV. A randomized, multicentric clinical trial is necessary to definitely conclude on the safety and efficacy of intravitreal ranibizumab for CNV in pathological myopia.

References

1 Soubrane G: Choroidal neovascularization in pathologic myopia: recent developments in diagnosis and treatment. Surv Ophthalmol 2008;53:121-138.

2 Grossniklaus HE, Green WR: Pathologic findings in pathologic myopia. Retina 1992; 12:127-133.

3 Ohno-Matsui K, Yoshida T, Futagami S, Yasuzumi K, Shimada N, Kojima A, Tokoro T, Mochizuki M: Patchy atrophy and lacquer cracks predispose to the development of choroidal neovascularisation in pathological myopia. Br J Ophthalmol 2003;87:570573.

Treated with Ranibizumab 
4 Cohen SY, Laroche A, Leguen Y, Soubrane G, Coscas GJ: Etiology of choroidal neovascularization in young patients. Ophthalmology 1996;103:1241-1244.

5 Avila MP, Weiter JJ, Jalkh AE, Trempe CL, Pruett RC, Schepens CL: Natural history of choroidal neovascularization in degenerative myopia. Ophthalmology 1984;91:15731581.

6 Hampton GR, Kohen D, Bird AC: Visual prognosis of disciform degeneration in myopia. Ophthalmology 1983;90:923-926.

7 Tabandeh H, Flynn HW Jr, Scott IU, Lewis ML, Rosenfeld PJ, Rodriguez F, Rodriguez A, Singerman LJ, Schiffman J: Visual acuity outcomes of patients 50 years of age and older with high myopia and untreated choroidal neovascularization. Ophthalmology 1999; 106:2063-2067.

8 Yoshida T, Ohno-Matsui K, Ohtake Y, Takashima T, Futagami S, Baba T, Yasuzumi K, Tokoro T, Mochizuki M: Long-term visual prognosis of choroidal neovascularization in high myopia: a comparison between age groups. Ophthalmology 2002;109:712-719.

9 Blinder KJ, Blumenkranz MS, Bressler NM, Bressler SB, Donato G, Lewis H, Lim JI, Menchini U, Miller JW, Mones JM, Potter MJ, Pournaras C, Reaves A, Rosenfeld P, Schachat AP, Schmidt-Erfurth U, Sickenberg M, Singerman LJ, Slakter JS, Strong HA, Virgili G, Williams GA, Verteporfin in Photodynamic Therapy Study Group: Verteporfin therapy of subfoveal choroidal neovascularisation in pathologic myopia: 2-year results of a randomized clinical trial - VIP report No 3. Ophthalmology 2003;110:667-672.

10 Silva RM, Ruiz-Moreno JM, Nascimento J, Carneiro A, Rosa P, Barbosa A, Carvalheira F, Faria Abreu JR, Cunha-Vaz JG: Short-term efficacy and safety of intravitreal ranibizumab for myopic choroidal neovascularization. Retina 2008;28:1117-1123.
11 Silva RM, Ruiz-Moreno JM, Rosa P, Carneiro A, Nascimento J, Rito LF, Cachulo ML, Carvalheira F, Murta JN: Intravitreal ranibizumab for myopic choroidal neovascularization: 12 months results. Retina 2010;30:407417.

12 Brown DM, Kaiser PK, Michels M, Soubrane G, Heier JS, Kim RY, Sy JP, Schneider S, ANCHOR Study Group: Ranibizumab versus verteporfin for neovascular age-related macular degeneration. N Engl J Med 2006; 355:1432-1444.

13 Rosenfeld PJ, Brown DM, Heier IS, Boyer DS, Kaiser PK, Chung CY, Kim RY, MARINA Study Group: Ranibizumab for neovascular age-related macular degeneration. N Engl J Med 2006;355:1419-1431.

14 Tong JP, Chan WM, Liu DT, Lai TY, Choy KW, Pang CP, Lam DS: Aqueous humor levels of vascular endothelial growth factor and pigment epithelium-derived factor in polypoidal choroidal vasculopathy and choroidal neovascularization. Am J Ophthalmol 2006; 141:456-462.

15 Monés JM, Amselem L, Serrano A, Garcia M, Hijano M: Intravitreal ranibizumab for choroidal neovascularization secondary to pathologic myopia: 12-month results. Eye 2009;23:1275-1280.

16 Lalloum F, Souied EH, Bastuji-Garin S, Puche N, Querques G, Glacet-Bernard A, Coscas G, Soubrane G, Leveziel N: Intravitreal ranibizumab for choroidal neovascularization complicating pathologic myopia. Retina 2010;30:399-406.

17 Rosenfeld PJ, Rich RM, Lalwani GA: Ranibizumab: phase III clinical trial results. Ophthalmol Clin North Am 2006;19:361-372.

18 Lai TY, Chan WM, Liu DT, Lam DS: Intravitreal ranibizumab for the primary treatment of choroidal neovascularization secondary to pathologic myopia. Retina 2009; 29:750-756.
19 Calvo-Gonzalez C, Reche-Futos J, Donate J, Fernandez-Perez C, Garcia-Feijoo J: Intravitreal ranibizumab for myopic choroidal neovascularization: factors predictive of visual outcome and need for retreatment. Am J Ophthalmol 2011;151:529-534.

20 Geitzenauer W, Kiss CG, Durbin MK, Abunto MT, Callan TM, Stetson PF, Wieland MR, Bressler NM, Gregori G, Schmidt-Erfurth UM: Comparing retinal thickness measurements from Cirrus spectral domain- and Stratus time domain-optical coherence tomography. Retina 2010;30:596-606.

21 Durbin M, Abunto T, Chang M, Lujan B: Retinal measurements: comparison between cirrus HD-OCT and stratus OCT. 2007. www. meditec.zeiss.com/C125679E00525939/ContainerTitel/CirrusOCT/\$File/retinal-measurements.pdf. (accessed June 1, 2011).

22 Abedi G, Patal P, Doros G, Subramanian ML: Transitioning from stratus OCT to cirrus OCT: a comparison and a proposed equation to convert central subfield macular thickness measurements in healthy subjects. Graefes Arch Clin Exp Ophthalmol 2011; 249:1353-1357.

23 Montero JA, Ruiz-Moreno JM: Verteporfin photodynamic therapy in highly myopic subfoveal choroidal neovascularisation. $\mathrm{Br} \mathrm{J}$ Ophthalmol 2003;87:173-176.

24 Axer-Siegel R, Ehrlich R, Weinberger D, Rosenblatt I, Shani L, Yassur Y, Priel E, Kramer M: Photodynamic therapy of subfoveal choroidal neovascularization in high myopia in a clinical setting: visual outcome in relation to age at treatment. Am J Ophthalmol 2004; 138:602-607.

25 Soubrane G, Coscas G: Choroidal neovascular membranes in degenerative myopia; in Ryan SJ, Ogden TE, Hinton DR, Schachat AP, Wilkinson CP (eds): Retina. St Louis, CV Mosby, 2006, vol 2: Medical Retina, pp 1115 1133 